Vol 13, Issue 4, 2020

\title{
EFFECTS OF SWISS BALL EXERCISE AND STRETCHING EXERCISE IN CHEST WALL MOBILITY AND SHOULDER RANGE OF MOTION AMONG POST-OPERATIVE BREAST CANCER WOMEN
}

\author{
REKHA K*, RESHMA RIHANA SM \\ Department of Saveetha College of Physiotherapy, Chennai, Tamil Nadu, India. Email: futurdreams88@gmail.com
}

Received: 14 January 2019, Revised and Accepted: 22 February 2020

\begin{abstract}
Objectives: The objectives of the study were to determine and compare the effects of Swiss ball exercises and stretching exercises in improving chest expansion, forced expiratory volume in one second (FEV1), and shoulder range of motion (ROM) among post-operative breast cancer women.
\end{abstract}

Methods: The study included 20 females who underwent surgery for breast carcinoma. Each group consists of 10 participants who were assessed for chest expansion at three levels, FEV1, and shoulder ROM for flexion and abduction. Group A was treated with Swiss ball exercises and Group B was treated with stretching exercises for a period of 4 weeks, 5 days/week following which post-test was performed same as of pre-test.

Results: Comparison between Swiss ball Group A and stretching Group B shows the chest expansion measurement at axillary level has a significant difference between the groups with $\mathrm{p}=0.0001$, fourth intercostal level showed a difference in mean with $\mathrm{p}=0.004$ and xiphisternal level p-value observed as (0.001), FEV1 between the group also shows significant changes in the post-test with a p=0.0481 and shoulder flexion ROM was increased in post-test when compared to pre-test scores with a $\mathrm{p}=0.0042$ and abduction ROM also showed a significant difference with $\mathrm{p}=0.0463$. Thereby, the post-test scores of Group A are higher than the Group B.

Conclusion: Exercise training on Swiss ball is more effective than stretching in treating post-operative breast cancer patients.

Keywords: Breast carcinoma, Post-operative breast cancer women, Swiss ball, Chest expansion.

(C) 2020 The Authors. Published by Innovare Academic Sciences Pvt Ltd. This is an open access article under the CC BY license (http://creativecommons. org/licenses/by/4. 0/) DOI: http://dx.doi.org/10.22159/ajpcr.2020.v13i4.36858

\section{INTRODUCTION}

Cancer is a disease characterized by proliferation of abnormal tumor cells. Breast cancer is the most commonly diagnosed cancer in female [1]. Indian medical council research data reported that breast cancer found to be the most common type of cancer in women with an incidence about 50-60\% cases in India. In 2011, 77,843 new cancer cases were recorded in Tamil Nadu of that 7931 women were diagnosed with breast cancer, which is slightly ahead of cervical cancer [2]. Genetic history, reduced physical activity, poor diet control, western lifestyle, and increased body mass index due to increased estrogen and estradiol hormone [3] found to be a major risk factor for premenopausal and postmenopausal women to develop breast cancer [4]. Even when the incidence of breast cancer among our population is increasing, with the effective methods of treatment and less invasive surgical approaches, improved outcomes are attained.

Patients who underwent breast cancer treatments usually have a generalized reduction in physical activity and also have an impact on social, emotional, and mental well-being affecting the quality of life [5]. Fatigue, pain, anxiety, and depression are the common symptoms found in breast cancer patients. Usually, the treatment approach for breast cancer includes mastectomy following adjuvant therapy such as hormone therapy and chemotherapy which reduce the recurrence of breast cancer but with few side effects. Chemotherapy includes long-term and short-term side effects such as fatigue, skin rash, cardiopulmonary toxicity, and brachial nerve palsy. All these side effects negatively influence the quality of life, especially among premature menopause women [1].

The surgical procedure such as mastectomy shows some effects on musculoskeletal system and pulmonary functions [6]. Upper limb motion is impaired in a mastectomy due to restriction of shoulder range of motion (ROM), pectoral muscle tightness which further limits forward flexion and horizontal abduction ROM. This happens due to the post-operative tightness, contractures, and radiation-induced fibrosis. Pectoral muscle shortening is more common in patients who undergo mastectomy; it further leads to contractures of costochondral and costovertebral joint and it reduces the rib cage motion due to sustained tightness, which further has an impact on postural changes such as protracted and depressed scapula, which in turn causes myofascial pain and rotator cuff disease; as a result, they affect the functionality and health-related quality of life [1]

For patients with mastectomy, abdominal muscles predominantly act in supine lying, as diaphragm moves, the cephalad pressure on the intraabdominal contents reduce the intra-thoracic size which further limits the activity of diaphragm and intercostal muscle, leading to shallow breathing pattern and increased respiratory rate, which result in decline of pulmonary functions especially involving forced vital capacity, forced expiratory volume in one second (FEV1) and functional residual capacity leading to atelectasis, and also found to have a ventilation- perfusion mismatch ratio leading to arterial hypoxemia. Therefore, stretching and strengthening of trunk and abdominal muscles help in treating the rib cage tightness, respiratory muscle weakness, and improve pulmonary functions [1]

Several studies show that exercises are effective in minimizing the side effects of breast cancer and also help in improving physical functions, quality of life among breast cancer survivors, and also have physiological and psychological benefits. Usually stretching exercise programs are emphasized in breast cancer patients. A low-load, prolonged passive stretching exercise of pectoral muscle is suggested [1,7]. Group and supervised exercise programs improve shoulder ROM and strength, and create a positive impact on pain and disability in breast cancer women, which emphasize on improving physical fitness and quality of life [8], 
Table 1: Comparison of pre-test and post-test values of chest expansion in Group A

\begin{tabular}{|c|c|c|c|c|c|c|}
\hline \multirow[t]{2}{*}{ Chest expansion } & \multicolumn{2}{|c|}{ Pre-test } & \multicolumn{2}{|c|}{ Post-test } & \multirow[t]{2}{*}{ t-value } & \multirow[t]{2}{*}{ p-value } \\
\hline & Mean & SD & Mean & SD & & \\
\hline Axillary level & 0.56 & 0.10 & 1.59 & 0.35 & 9.06 & 0.0001 \\
\hline Xiphisternal level & 1.26 & 0.48 & 1.83 & 0.54 & 4.74 & 0.001 \\
\hline
\end{tabular}

SD: Standard deviation

Table 2: Comparison of pre-test and post-test values of chest expansion in Group B

\begin{tabular}{|c|c|c|c|c|c|c|}
\hline \multirow[t]{2}{*}{ Chest expansion } & \multicolumn{2}{|c|}{ Pre-test } & \multicolumn{2}{|c|}{ Post-test } & \multirow[t]{2}{*}{ t-value } & \multirow[t]{2}{*}{ p-value } \\
\hline & Mean & SD & Mean & SD & & \\
\hline Axillary level & 0.84 & 0.37 & 1.14 & 0.47 & 4.74 & 0.001 \\
\hline $4^{\text {th }}$ intercostal level & 1.06 & 0.19 & 1.51 & 0.37 & 2.86 & 0.019 \\
\hline Xiphisternal level & 1.44 & 0.13 & 1.99 & 0.63 & 2.85 & 0.019 \\
\hline
\end{tabular}

SD: Standard deviation

and do not precipitate lymph edema in post-operative breast cancer patient [9]. In general, Swiss ball exercises use to improve core stability, muscle strength, muscle endurance, balance, cardio endurance, and functional fitness. However, not many studies report the effects of Swiss ball in pulmonary functions and musculoskeletal changes among mastectomy. Thereby, in our study, we propose to determine the effects of Swiss ball exercises and stretching exercise in improving chest expansion, FEV1, and shoulder ROM among post-operative breast cancer patients.

\section{METHODS}

A quasi-experimental study was conducted at Saveetha Medical College Hospital. Scientific Review Board Approval and Ethical Committee approval was obtained before the study. Following the ethical clearance, data collection procedure was initiated. Detailed procedure was clearly explained to the patient by providing information sheet and written informed consent was taken from all the participants. A consecutive sampling technique used to allocate the participants equally into two groups by Odd-Even method.

Twenty females who underwent surgery for breast carcinoma were selected based on inclusion and exclusion criteria. The study included those aged between 40 and 60 years, patients who underwent unilateral breast cancer surgery within 1 month period following surgery and patients who underwent breast conservation surgery. The study excluded those with movement limitation before surgery evaluated with a difference $>20^{\circ}$ in flexion and abduction, chronic diseases - rheumatoid arthritis, low back pain involving disc problems, shoulder dysfunction adhesive capsulitis, rotator cuff disease, recent fractures, unstable vital signs, cardiovascular diseases, acute or chronic respiratory diseases, systemic disease affecting muscles and joints, osteoporosis, and those patients who are not willing for 4 weeks follow-up program.

Each group consists of 10 participants. Both the group participants were assessed for chest expansion at three levels axillary level, $4^{\text {th }}$ intercostal level, and xiphisternal level using inch tape, FEV1 was measured using a computerized spirometer and shoulder ROM for flexion and abduction measured with universal goniometer as pre-test outcomes. Following the intervention period of 4 weeks, same tests were repeated for post-test. Group A (experimental group) was treated with Swiss ball exercise and diaphragmatic breathing exercises. Group B (control group) was treated with stretching exercise and diaphragmatic breathing exercises. Both the group participants were treated for a period of 4 weeks, 5 days/week.

\section{Group A: Swiss ball exercises}

\section{Swiss ball roll away}

Patient is asked to sit with Swiss ball on either side, resting their palm on the ball, with the shoulders abducted laterally and palms placed over the Swiss ball tightly. Make sure both the elbows are extended. Asked them to sway the trunk laterally by leaning on one side and on the other side; repeat the exercise.

\section{Swiss ball roll on}

Patient is asked to sit with Swiss ball on either sides, with the elbows and hands rested on the ball, with shoulders slightly abducted with elbows flexed, and ask to roll the ball away from the body in forward and backward direction; repeat the exercise.

\section{Swiss ball hold on}

The patient is asked to lie on crook lying by holding the Swiss ball between the hands above the head. The patient is asked to lift the ball and bring it back to tummy level; repeat the exercise alternatively.

\section{Swiss ball hold up}

The patient is asked to lie on crook lying position by holding the Swiss ball between the hands, facing forward with shoulders in $90^{\circ}$ flexion and elbow extended, and asked to perform an internal rotation of shoulder and external rotation of shoulder; repeat the exercise alternatively.

\section{Swiss ball cat press}

Patient asked to sit on a mat with hands-on Swiss ball which has been placed in front of the patient, with elbows stretched and asked to perform trunk flexion and extension; repeat the exercise alternatively.

\section{Group B: Stretching exercises \\ Butterfly stretch}

With the patient on lying position, ask to place both the hands behind the neck, with their shoulders apart and elbows out to the side, and ask them to move their elbows together in front of their body until they touch, will feel a stretch across the shoulder; hold it and then relax; return to starting position and repeat the stretch.

\section{Shoulder blade squeeze}

With patient on sitting position, with back straight not resting against the back of the chair, having the arms at their side with the elbows bent and ask them to squeeze the shoulder blades together by bringing the elbows behind, will feel a stretch across the shoulder blade; hold it and then relax; make sure that their shoulder level is maintained on doing the stretch; return to starting position and repeat the stretch.

\section{Shoulder stretch}

Patient standing close to the wall with hands resting on it and ask them to climb the wall, reaching as high as they can, until they feel the stretch; hold it and then relax; make sure as they climb up, their shoulders are 
placed far away from their ears; return to starting position and repeat the stretch.

\section{Corner stretch}

Patient standing in a corner, with their elbows bend and forearm resting on the wall, one on each side of the corner. Make sure the elbows placed closed to the shoulder height as possible. Ask to keep their arms and feet in place and move the chest towards the corner, with forearm and hands pressing against the wall; they will feel a stretch across the chest and shoulder; hold it and then relax; return to starting position and repeat the stretch.

\section{Chest stretch}

Patient standing beside the wall, with one of the palm resting on the wall. Make sure the hand is placed closed to the shoulder height as possible with elbow bend. Ask to keep their arms and feet in place and turn the body away from the wall, with palm pressing against the wall; they will feel a stretch across the chest; hold it and then relax; return to starting position and repeat the stretch.

Both groups were treated with diaphragmatic breathing exercises.

\section{Diaphragmatic breathing exercise}

Patient is asked to sit straight with her shoulder girdle and upper chest relaxed with head and neck supported. Therapist must place her hands over the lower costal margin and over the upper abdomen of the patient. To facilitate and feel the diaphragm movement. Patient is asked to blow out gently and be aware of the movement. At the end of expiration, therapist gently applies pressure over the diaphragm and commands the patient to breathe in when applying pressure which serves as the resistance for diaphragm, and it helps to strengthen the diaphragm. The patient is assisted by the therapist by repeating the same procedure until she is mastered. Four weeks of treatment protocol includes 1 session/day, 10 repetitions, and 5 days/week.

\section{RESULTS}

Twenty females who underwent surgery for breast carcinoma were selected based on inclusion criteria. The collected data were tabulated and analyzed using descriptive and inferential statistics. To all parameters, mean and standard deviation (SD) were calculated. A paired t-test was used to analyze significant changes between pre-test and post-test measurements within the groups. An Independent t-test was used to analyze significant changes between two groups.

Statistical analysis of quantitative data shows a significant difference between Group A and Group B for all the outcomes and also within the group, the difference has been observed. Table 3 shows that the posttest mean value of chest expansion measurement at an axillary level in Group A is 1.59 (SD 0.35) and post-test mean value of chest expansion measurement in Group B is 1.14 (SD 0.47), Group A shows the significant difference with $\mathrm{p}=0.025$. The post-test mean value of chest expansion measurement at fourth intercostal space in Group A is 1.60 (SD 0.52) and post-test mean value of chest expansion measurement at fourth intercostal space in Group B is 1.51 (SD 0.37), Group A considered to be not statistically significant with p 0.661 showed in Table 3 . The posttest mean value of chest expansion measurement at xiphisternal level in Group A is 1.83 (SD 0.54) and post-test mean value of chest expansion measurement at xiphisternal level in Group B is 1.99 (SD 0.63), Group A shows the significant difference with $\mathrm{p}=0.547$ showed in Table 3 .

Table 5 shows that the post-test mean value of FEV1 in Group A is 101.40 (SD 14.52) and post-test mean value of FEV1 in Group B is 89.50 (SD 10.19), Group A shows the significant difference with p-value (0.0481). Table 8 shows that the post-test mean value of shoulder flexion in Group A is 159.80 (SD 6.80) and is higher than the post-test mean in Group B 147.20 (SD 10.80), this shows that Group A shows the significant difference with $\mathrm{p}=0.0042$. The post-test mean value of shoulder abduction in Group A is 128.60 (SD 6.83) and is higher than the post-test mean in Group B 119.80 (SD 11.06), Group A shows the significant difference with $\mathrm{p}=0.0463$ showed in Table 8.

\section{DISCUSSION}

Breast cancer is the most frequently diagnosed malignant tumor among women worldwide; the complications of the treatment are enormous which have an impact in daily activities and quality of life in women [7]. An increase in incidence has made way for improvement in advanced treatment approaches which had an impact among breast cancer survival [10]. Breast cancer patients showed marked impairment in muscle strength and joint dysfunction before and after anticancer treatment [6]. Incidences have been increasing over the past decades for both premenopausal and postmenopausal women. Although the incidence of breast cancer increases during postmenopausal years, it is the leading cause of cancer death in women younger than 50 years of age [1].

A total of 185,660 cancer notifications have been registered with Tamil Nadu Cancer Registry Project for 2012-2014 from 964 data sources. The preliminary data for 2012, after eliminating duplicate notifications of the same cases, revealed of 53,363 new cancer cases in Tamil Nadu. Of this, there were 23,149 men and 30,214 women. Chennai has the highest incidence rate among all the 32 districts in the state. The city has a crude incidence rate of 120.4 , while Nilgiris has 30.9 , the lowest among districts. Among women, breast cancer was slightly ahead of cervix cancer. Data processing for 2013-2014 is in progress [11].

Post-operative breast cancer patients tend to have a poor functional status and reduced quality of life which is commonly caused due to pain, radiation-induced fibrosis, surgical scarring, or intercostal brachial nerve damage, which can persist from months to years after surgery. Anxiety, depression, anger, fatigue, insomnia, hot flashes, mood disturbances, poor body image, [12] swelling, weakness, stiffness, limited ROM [13] declined cardiovascular, and pulmonary functions [10] are the other common sequel. Few studies show that exercises are known to decrease anxiety and it helps to regain functional ability as early as possible [14]. Sagen et al. also reported about the risk factors of breast cancer surgery, stating about reduced handgrip strength, restricted shoulder mobility and shoulder abduction evoked pain, numbness in chest wall, and tightness, pulling or stretching in the arm, and disruption in physical and psychological dimensional quality of life [15].

Physical activity and functional improvement are an integral part in women's health. When it is disturbed, it affects their growth as an individual in family and society. Hence, to provide an ultimate care, we proposed this study to determine the effects of Swiss ball exercise and stretching exercise among post-operative breast cancer women. This study included two groups with 20 post-operative breast cancer patients who underwent surgical treatment within a period of 1 month. Each group consisted of 10 participants in Group A and Group B. Group A experimental group received Swiss ball exercise and diaphragmatic breathing exercise, Group B received stretching exercise and diaphragmatic breathing exercise. The study investigated on the effects of Swiss ball exercise and stretching exercise in chest expansion, FEV1, and shoulder flexion and abduction ROM.

Based on scientific data, a general rehabilitation program with aerobic exercise, stretching, and strengthening exercises found to be an effective approach in patients with mastectomy. Core stability exercises were also implemented to prevent misalignment and maintain axial muscle strength. Multi-model deterioration is common among surgically treated breast cancer patients. The absence of exercise programs among patients of chronic disease, including cancer, has a great impact on energy deterioration leading to lethargy and fatigue affecting physical functions, muscle weakness, social, and cognitive functions [5]. 
Table 3: Comparison of post-test values of chest expansion measurement in Group A and Group B

\begin{tabular}{|c|c|c|c|c|c|c|}
\hline \multirow[t]{2}{*}{ Chest expansion } & \multicolumn{2}{|c|}{ Group A } & \multicolumn{2}{|c|}{ Group B } & \multirow[t]{2}{*}{ t-value } & \multirow[t]{2}{*}{ p-value } \\
\hline & Mean & SD & Mean & SD & & \\
\hline Axillary level & 1.59 & 0.35 & 1.14 & 0.46 & 2.451 & 0.025 \\
\hline Xiphisternal level & 1.83 & 0.54 & 1.99 & 0.63 & 0.614 & 0.547 \\
\hline
\end{tabular}

SD: Standard deviation

Table 4: Comparison of pre-test and post-test values of FEV1 in Group A and Group B

\begin{tabular}{llllllll}
\hline \multirow{2}{*}{ FEV1 } & \multicolumn{2}{l}{ Pre-test } & & \multicolumn{2}{l}{ Post-test } & \multirow{2}{*}{ t-value } & p-value \\
\cline { 2 - 3 } & Mean & SD & & Mean & SD & & \\
\hline Group A & 85.90 & 10.33 & & 101.40 & 14.52 & 5.26 & 0.0005 \\
Group B & 83.30 & 6.99 & 89.50 & 10.19 & 2.47 & 0.0356 \\
\hline
\end{tabular}

SD: Standard deviation, FEV1: Forced expiratory volume in one second

Table 5: Comparison of post-test values of FEV1 in Group A and Group B

\begin{tabular}{llllllll}
\hline \multirow{2}{*}{ Parameter } & \multicolumn{2}{l}{ Group A } & & \multicolumn{2}{l}{ Group B } & \multirow{2}{*}{ t-value } & p-value \\
\cline { 2 - 3 } & Mean & SD & & Mean & SD & & \\
\hline FEV1 & 101.40 & 14.52 & & 89.50 & 10.19 & 2.12 & 0.0481 \\
\hline
\end{tabular}

SD: Standard deviation, FEV1: Forced expiratory volume in one second

Table 6: Comparison of pre-test and post-test values of shoulder flexion and abduction ROM in Group A

\begin{tabular}{llllllll}
\hline $\begin{array}{l}\text { Shoulder } \\
\text { ROM }\end{array}$ & \multicolumn{2}{l}{ Pre-test } & & \multicolumn{2}{l}{ Post-test } & t-value & p-value \\
\cline { 2 - 3 } & Mean & SD & & Mean & SD & & \\
\hline $\begin{array}{l}\text { Shoulder } \\
\text { flexion }\end{array}$ & 142.80 & 6.61 & & 159.80 & 6.80 & 16.46 & 0.0001 \\
$\begin{array}{l}\text { Shoulder } \\
\text { abduction }\end{array}$ & 94.10 & 3.48 & & 128.60 & 6.83 & 23.47 & 0.0001 \\
\hline
\end{tabular}

SD: Standard deviation, ROM: Range of motion

Exercise intervention for cancer patient aimed at improving the patient quality of life and physical activity, which creates a sense of control and confidence in the patient by reducing stress and anxiety, which also helps in increasing acceptance of illness. The advantage of physical rehabilitation programs increases the quality of life, positive emotions decrease stress and improve physical functions. The rehabilitation process reduces pain, fatigue, and improve symptoms, especially among patients recovering from breast cancer $[5,14]$.

From this study, we found that Swiss ball exercise is effective in improving chest expansion, FEV1, and shoulder flexion and abduction ROM. As this study was also supported by various other studies, "The Swiss ball can be a useful physiotherapeutic resource in promoting adequate functional recovery and, consequently, providing a better quality of life, besides being playful and having a low financial cost" [16].

In this study, among Group A, five different types of Swiss ball exercises were given which was supported by Mariano et al. stating that a positive response in shoulder flexion and abduction movements and also minimized the incidence of cicatricial adhesion in women who were surgically treated for breast cancer [16]. Control group, Group B, is treated with stretching exercises general pectoral stretches which increase the extensibility of soft tissue, ROM, and flexibility to prevent muscle shortening [17]. Recent studies stated that the use of Swiss ball exercise is capable of increasing the shoulder muscle activity of pectoralis major and triceps, by improving the muscular demand required to maintain
Table 7: Comparison of pre-test and post-test values of shoulder flexion and abduction ROM in Group B

\begin{tabular}{llllllll}
\hline \multirow{2}{*}{$\begin{array}{l}\text { Shoulder } \\
\text { ROM }\end{array}$} & \multicolumn{2}{l}{ Pre-test } & & \multicolumn{2}{l}{ Post-test } & \multirow{2}{*}{ t-value } & p-value \\
\cline { 2 - 3 } & Mean & SD & & Mean & SD & & \\
\hline $\begin{array}{l}\text { Shoulder } \\
\text { flexion }\end{array}$ & 140.10 & 11.57 & & 147.20 & 10.08 & 6.22 & 0.0002 \\
$\begin{array}{l}\text { Shoulder } \\
\text { abduction }\end{array}$ & 95.50 & 6.85 & & 119.80 & 11.06 & 8.19 & 0.0001 \\
\hline
\end{tabular}

SD: Standard deviation, ROM: Range of motion

Table 8: Comparison of post-test values of shoulder flexion and abduction ROM in Group A and Group B

\begin{tabular}{llllllll}
\hline $\begin{array}{l}\text { Shoulder } \\
\text { ROM }\end{array}$ & \multicolumn{2}{l}{ Group A } & & \multicolumn{2}{l}{ Group B } & \multirow{2}{*}{ t-value } & p-value \\
\cline { 2 - 3 } & Mean & SD & & Mean & SD & & \\
\hline $\begin{array}{l}\text { Shoulder } \\
\text { flexion }\end{array}$ & 159.80 & 6.80 & & 147.20 & 10.08 & 3.28 & 0.0042 \\
$\begin{array}{l}\text { Shoulder } \\
\text { abduction }\end{array}$ & 128.60 & 6.83 & & 119.80 & 11.06 & 2.14 & 0.0463 \\
\hline
\end{tabular}

SD: Standard deviation, ROM: Range of motion

postural stability and improves joint proprioception [18]. Swiss ball was found to be effective as the exercises stretch and also strengthen the muscles of the shoulder joint and scapula by increasing the ROM, whereas stretching helps in the prevention of muscle shortening. At the end of 4 week treatment with stretching exercises, especially pectoral stretch, an improvement in shoulder horizontal abduction was noted but did not lead to an improvement in upper extremity symptoms, functions, and quality of life [7]

Diaphragmatic breathing exercise helps in reducing the respiratory rate and improves tidal volume and pulmonary functions; it is a common conventional protocol followed immediately after any surgery to maintain the tidal volume of the lung and to prevent secretion accumulation and atelectasis [19]. Hence, we included diaphragmatic breathing exercises for both groups. This study included a sequence of exercises with Swiss ball along with breathing exercise as it mobilizes the chest wall which can improve chest expansion and FEV1. Swiss ball training is very helpful as it improves oxygen delivery and decreases blood lactate and carbon dioxide output; by that, it helps in improving aerobic capacity and increases muscle strength and desensitization to dyspnea [20]. The findings suggested that Swiss ball exercises motivate the patient on indulging themselves more on exercise regime which helped them in the improvement of functional capacity. Swiss ball exercise, along with breathing exercise, showed a significant improvement in pulmonary function, especially FEV1, and also had a positive effect on physical functions, especially shoulder ROM.

\section{CONCLUSION}

Post-operative breast cancer patients found to have an increased risk of reduced chest wall mobility due to tight fibrous scar tissues and restricted shoulder functions due to the excision of the pectoral muscle. Hence, Swiss ball exercises, along with breathing exercise, were found to improve chest wall mobility and shoulder ROM among breast 
cancer patients. Therefore, from this study, it is concluded that exercise training on Swiss ball is more effective in treating post-operative breast cancer patients.

\section{AUTHORS' CONTRIBUTIONS}

K. Rekha organized clinical data, data interpretation, guided, and reviewed the manuscript.

Reshma Rihana compiled the review of literature, preparation of the manuscript, and helped in clinical work.

\section{CONFLICTS OF INTEREST}

None.

\section{AUTHORS' FUNDING}

Self-funding project.

\section{REFERENCES}

1. Black JH, Meier RH. Cancer Rehabilitation. American Academy of Physical Science and Rehabilitation; 2015. Available from:http://ww w. emedicine.medscape.com/article/320261-overview\#a2(medscape).

2. Anderson RT, Kimmick GG, McCoy TP, Hopkins J, Levine E, Miller G, et al. A randomized trial of exercise on well-being and function following breast cancer surgery: The RESTORE trial. J Cancer Surviv 2012;6:172-81.

3. Key TJ, Appleby PN, Reeves GK, Roddam A, Dorgan JF, Longcope C, et al. Body mass index, serum sex hormones, and breast cancer risk in postmenopausal women. J Natl Cancer Inst 2003;95:1218-26.

4. Hirose K, Tajima K, Hamajima N, Inoue M, Takezaki T, Kuroishi T, et al. A large-scale, hospital-based case-control study of risk factors of breast cancer according to menopausal status. J Jpn Cancer Res1995;86:146-54.

5. Do J, Cho Y, Jeon J. Effects of a 4-week multimodal rehabilitation program on quality of life, cardiopulmonary function, and fatigue in breast cancer patients. J Breast Cancer 2015;27:87-95.

6. Klassen O, Sehmidt ME, Ulrich CM, Schneeweiss A, Potthoff K, Steindorf $\mathrm{K}$, et al. Muscle strength in breast cancer patient receiving different treatment regimes. J Cachexia Sarcopenia Muscle 2017;8:305-16.
7. Lee SY, Sim MK, Do J, Jeong SY, Jeon JY. Pilot study of effective methods for measuring and stretching for pectoral muscle tightness in breast cancer patients. J Phys Ther Sci 2016;28:3030-5.

8. Ceprnja D, Maka K. Implementation of an exercise program in breast cancer rehabilitation to improve shoulder outcomes, a pilot study. Int $\mathrm{J}$ Allied Health Sci Pract 2015;13:1-8.

9. Kilbreath SL, Refshauge KM, Beith JM, Ward LC, Lee M, Simpson JM, et al. Upper limb progressive resistance training and stretching exercises following surgery for early breast cancer: A randomized controlled trial. Breast Cancer Res Treat 2012;133:667-76.

10. Schneider CM, Hsieh CC, Sprod LK, Carter SD, Hayward R. Effects of supervised exercise training on cardiopulmonary function and fatigue in breast cancer survivors during and after treatment. Cancer 2007;110:918-25.

11. Krishnan S. Cancer of Stomach and BreastMostCommoninTamilnadu Times of India;2015.Available from:http://www.timesofindia. indiatimes.com/city/chennai/cancers-of-stomach-and-breast -mo st- common-in-tn/articleshow/48716855.cms.

12. Shimozuma K, Ganz PA, Petersen L, Hirji K. Quality of life in the first year after breast cancer surgery: Rehabilitation needs and patterns of recovery. Breast Cancer Res Treat 1999;56:45-57.

13. Maunsell E, Brisson J, Deschhenes L. Arm problems and psychological distress after surgery for breast cancer. Can J Surg 1993;36:315-20.

14. Keays KS, Harris SR, Lucyshyn JM, Maclntyre DL. Effects of pilates exercises on shoulder range of motion, pain, mood and upper extremity function in women living with breast cancer: A pilot study. Phys Ther 2008;88:494-510.

15. Sagen A, Kaaresen R, Sandvik L, Thune L, Risberg MA. Upper limb physical function and adverse effects after breast cancer surgery: A prospective 2.5 year follow up study and preoperative measures. Arch Phys Med Rehabil 2014;95:875-81.

16. Mariano K, Diniz M, Silva AT, Silva J, Vasconcelos L, Branco M. Effect of exercises with swiss ball previously applied to radiation therapy for breast cancer. Rev Neurocienc 2015;23:55-61.

17. Kisner C, Colby LA. Therapeutic Exercise, Foundation and Techniques. 6th ed. New Delhi: Jaypee Brothers Medical Publications; 2013.

18. Sandhu JS, Mahajan S, Shenoy S. An electromyographic analysis of shoulder muscle activation during push-up variations on stable and labile surfaces. Int J Shoulder Surg 2008;2:30-5.

19. Porter SB. Tidy's Physiotherapy. 15th ed. Amsterdam: Elsevier Publication; 2013

20. Carriere B. Theory, Principal and Practical Application of Swiss Ball Physical Therapy. Berlin: Springer; 1998. p. 92-100. 